BMJ Open Sport \& Exercise Medicine

\title{
Spatiotemporal characteristics of motor actions by blind long jump athletes
}

\author{
Miguel Angel Torralba, ${ }^{1}$ José María Padullés, ${ }^{2}$ Jose Luis Losada, ${ }^{3}$ \\ Jose Luis López ${ }^{2}$
}

To cite: Torralba MA, Padullés JM, Losada JL, et al. Spatiotemporal characteristics of motor actions by blind long jump athletes. BMJ Open Sport Exerc Med 2017;3: 000252. doi:10.1136/bmjsem-2017000252

Accepted 15 July 2017

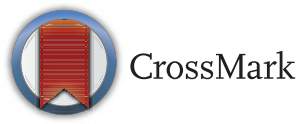

${ }^{1}$ Did.CS,EM,EF,EVP, Barcelona University, Barcelona, Spain

${ }^{2}$ Rendiment, INEFC Performance, Barcelona, Spain

${ }^{3}$ Psicologia Social i Psicologia Quantitativa, Universitat de Barcelona, Barcelona, Spain

Correspondence to Dr Miguel Angel Torralba, Universitat de Barcelona, F. Education, Campus Mundet. Pg Vall d'Hebron 171. Barcelona, Barcelona, ES 08007, Spain; torralba@ub. edu, Dr José María Padullés, INEFC - Av de l'Estadi s/n 08038 Barcelona; jmpadu@ gmail.com, Dr Jose Luis Losada, F Psicologia, Pg Vall d'Hebron 171, 08035 Barcelona; jlosada@ub.edu and Dr Jose Luis López; jl. lopez@uvic.cat

\section{ABSTRACT}

Background Blind people depend on spatial and temporal representations to perform activities of daily living and compete in sport.

Objective The aim of this study is to determine the spatiotemporal characteristics of long jumps performed by blind athletes and compare findings with those reported for sighted athletes.

Methods We analysed a sample of 12 male athletes competing in the F11 Long Jump Finals at the Paralympic Games in London 2012. Performances were recorded using four high-speed cameras, and speeds were measured using a radar speed gun. The images were processed using validated image analysis software.

Results The long jump run-up is shorter in blind athletes than in sighted athletes. We observed statistically significant differences for body centre of mass velocity and an increase in speed over the last three strides prior to take-off, contrasting with reports for sighted athletes and athletes with less severe visual impairment, who maintain or reduce their speed during the last stride. Stride length for the last three strides was the only spatial characteristic that was not significantly associated with effective jump distance. Blind long jumpers extend rather than shorten their last stride. Contact time with the take-off board is longer than that reported for sighted athletes.

Conclusion The actions of blind long jumpers, unlike those without disabilities, do not vary their leg actions during the final runway approach for optimal placement on the take-off board.

\section{INTRODUCTION}

Physically impaired people frequently need assistance to perform activities of daily living and compete in sport. ${ }^{1}$ Blind athletes, for example, require assistance from a sighted guide. The organisation, identification and interpretation of sensory inputs to represent and understand one's surroundings are among the most important basic psychological processes. ${ }^{2-7}$

Space, like time, is not an innate notion. In sport, athletes slowly become aware of their surroundings through an initial perception of their bodies in space and the ensuing changes that occur, such as motor and sensory responses. Conceptualisation of

\section{What are the findings?}

- Visually impaired long jump athletes are required to compete with the same degree of visual impairment and under the same conditions in competitions, thereby favouring the development of spatiotemporal skills and promoting fair and equitable competition.

- Stride length was the only spatial variable that was not significantly associated with effective jump distance.

- Long jump requires blind athletes to develop refined spatial orientation skills.

How might it impact on clinical practice in the future?

Sports for individuals with physical impairments are designed to mirror sports practised by people without such impairments, although they incorporate certain modifications that require working with specialists to favour the necessary adaptations and facilitate the participation and motor and perceptual development of people with impairments.

- The practice of sport, and long jump in particular, helps blind people to develop perceptual skills that may help them in their everyday activities.

- Such exercises may also help visually impaired children to develop perceptual skills during early growth phases.

position, location, direction and distance is necessary for efficient motor performance. ${ }^{89}$ Spatial representation in blind people, however, is a slower, more complex process that requires accurate information and adequate training.

Space is generally perceived from the position of an object in space, and the information needed for processing this is usually provided by vision, touch or kinesthetic senses. The understanding of space is additionally complemented by the orientation of the person's body in 
relation to the surrounding physical space. Spatial perceptual skills encompass the ability to determine the position of one's body and objects in space, the ability to use spatial references, and the ability to successfully navigate this space. ${ }^{10} 11$

People are considered blind when they have total vision loss or light perception only; they have a visual acuity of 0.05 or less and a field radius of less than $10^{\circ} .8$ The International Paralympic Committee classifies visually impaired athletes into three sport classes known as T/F11-12-13. Those with the most severe visual impairment (ie, very low visual acuity and/or no light perception) are included in sport class T/F $11 .^{12} 13$

Long jump has featured as a paralympic sport since $1976 .{ }^{14}$ All athletes are required to wear opaque glasses or equivalent during competition to ensure equal level of visual impairment. ${ }^{15}$ They thus need to follow the instructions of a sighted guide in their approach to the jump, which ends in a pit measuring $1.00 \mathrm{~m} \times 1.22 \mathrm{~m} .{ }^{12}$ The approach, or runup, is one of the key components of a successful jump. It is largely dependent on consistency of stride length, number of strides and the achievement of an optimal speed just before take-off. ${ }^{16-26}$

Sighted athletes can adjust their approach during the final phase of the run-up; blind athletes, however, cannot make this visual adjustment, and it could therefore be hypothesised that any changes in final strides would be the result of training targeting the take-off action, with no adjustments in final approach. ${ }^{27} 28$

The aim of this study was to determine the spatiotemporal characteristics of long jumps performed by blind athletes in the F11 sport class at the Paralympic Games in London, with a focus on variables corresponding to the last three strides taken before take-off and a comparison with findings reported for sighted long jumpers.

\section{Ethical considerations}

The study was approved by the bioethics committee at the University of Barcelona (IRB00003099). Anonymity was guaranteed, and the study was conducted in full compliance with the principles of the fifth revision of the Declaration of Helsinki of the World Medical Association (October 2000).

\section{METHODS}

\section{Participants}

The sample consisted of 12 male athletes (mean $\pm \mathrm{SD}$ height $1.79 \pm 0.08 \mathrm{~m}$, body mass $73.7 \pm 6.4 \mathrm{~kg}$ and official distance of $5.82 \pm 0.45 \mathrm{~m}$ ) from 10 countries who participated in the F11 Long Jump Finals at the XIV Paralympic Games held in London.

\section{Procedure}

All the jumps made by the 12 athletes were videorecorded to analyse spatiotemporal and mechanical characteristics of the last three strides in the run-up and take-off phases of the jumps.

The following temporal variables were studied: contact time $\left(t_{C}\right)$, flight time $\left(t_{\mathrm{FL}}\right)$, stride time $\left(\mathrm{t}_{\mathrm{STR}}\right)$, calculated as $t_{\mathrm{STR}}=\mathrm{t}_{\mathrm{C}}+_{\mathrm{tFL}}$, and stride frequency (SF), calculated as $\mathrm{SF}=1 / \mathrm{t}_{\mathrm{STR}}$. The spatial variables were official jump distance, stride length (SL) and body centre of mass $(\mathrm{BCM})$ height $\left(\mathrm{h}=1.226 \times \mathrm{t}_{\mathrm{FL}}^{2}\right)$ during the aerial phase of each stride.

Spatiotemporal variables included horizontal BCM velocity $\left(\mathrm{V}_{\mathrm{BCM}}\right)$, stride speed $\left(\mathrm{V}_{\mathrm{STR}}=\mathrm{SF} \times \mathrm{SL}\right)$ vertical speed $\left(\mathrm{Vy}=\mathrm{g} \times \mathrm{t}_{\mathrm{FL}} / 2\right)$, speed at moment of take-off $(\mathrm{Vr}=$ $\left.\left(\mathrm{V}_{\mathrm{BCM}}^{2}+\mathrm{Vy}^{2}\right)^{0.5}\right)$ and take-off angle $\left(\mathrm{a}=\tan ^{-1}\left(\mathrm{Vy} / \mathrm{V}_{\mathrm{BCM}}\right)\right.$.

The data were analysed from video recordings captured using four EXILIM Highspeed EX-F1 cameras $(300 \mathrm{~Hz})$ (Casio, Japan), validated by Nojima. ${ }^{29} \mathrm{~V}_{\text {BCM }}$ was measured with a Stalker II Pro radar speed gun (Applied ConceptSTR, Texas, USA).

Kinovea V.0.8.15 (available at http://www.kinovea. org) was used to display the video recordings frame by frame. ${ }^{30}$ Data were extracted by two researchers experienced in the analysis of high-speed recordings in two sessions at least 7 days apart.

The accuracy of the times recorded was verified by calculating interobserver reliability. A third experienced observer re-examined $10 \%$ of the recorded data. The data matched in $57 \%$ of cases. In $36 \%$ of cases, there was a difference of one frame, and in the remaining $7 \%$ there was a difference of two frames. The two-frame difference corresponded to $0.0006 \mathrm{~s}$, which was the equivalent of an error of $1.3 \%$ for the calculation of SF. The intraclass correlation coefficient was $0.9945 \quad(95 \%$ CI 0.9888 to 0.9974).

One-way repeated measures analysis of variance (ANOVA) was used to compare the means of the variables analysed in the last three strides of the run-up for all athletes. The independent variable, or withinsubjects factor, was the result of the jump and there were 11 dependent variables.

A Bonferroni post-hoc test was used to correct for multiple comparisons. This is the most conservative of the multiple testing correction methods. It is similar to the t-test, but the error $(0.05)$ is divided by the number of comparisons made. The null hypothesis tested was that the means of the different strides would be the same, and the alternative hypothesis was that they would be significantly different.

The assumptions in such a design are normality of distribution and sphericity. As the assumption of normality was violated, the alternative non-parametric Friedman test was used to test for significant differences between the strides. This test does not, 


\begin{tabular}{lllllll}
\hline Table 1 & Friedman test & & & & \\
\hline Variable & Friedman & df & $\mathbf{p ~ V a l u e ~}$ & Median 1 & Median 2 & Median 3 \\
\hline $\mathrm{a}$ & 18.426 & 2 & $9.976^{\mathrm{e}-05}$ & 2.80 & 4.30 & 4.35 \\
$\mathrm{SF}$ & 12.905 & 2 & 0.0011 & 4.50 & 4.00 & 4.05 \\
$\mathrm{~h}$ & 18.426 & 2 & $9.976^{\mathrm{e}-05}$ & 0.85 & 2.10 & 1.95 \\
$\mathrm{SL}$ & 4.5 & 2 & 0.105 & 2.15 & 2.20 & 1.99 \\
$\mathrm{t}_{\mathrm{C}}$ & 20.723 & 2 & $3.162^{\mathrm{e}-05}$ & 0.13 & 0.11 & 0.12 \\
$\mathrm{t}_{\mathrm{FT}}$ & 18.167 & 2 & 0.0001 & 0.08 & 0.13 & 0.12 \\
$\mathrm{t}_{\mathrm{STR}}$ & 17.333 & 2 & 0.0001 & 0.22 & 0.25 & 0.25 \\
$\mathrm{Vr}_{\mathrm{r}}$ & 18.541 & 2 & $9.418^{\mathrm{e}-05}$ & 8.40 & 8.30 & 8.20 \\
$\mathrm{~V}_{\mathrm{STR}}$ & 18.5 & 2 & $9.611^{\mathrm{e}-05}$ & 9.60 & 9.00 & 8.05 \\
$\mathrm{Vx}$ & 20.667 & 2 & $3.253^{\mathrm{e}-05}$ & 8.38 & 8.26 & 8.18 \\
$\mathrm{Vy}$ & 18.465 & 2 & $9.784^{\mathrm{e}-05}$ & 0.40 & 0.60 & 0.60 \\
\hline & & & & &
\end{tabular}

however, indicate which pairs of conditions are different.

$$
X_{r}^{2}=\frac{12}{H K(K+1)} \sum R c^{2}-3 H(K+1)
$$

where $X_{r}^{2}$ is the Friedman ANOVA statistic by ranks, $H$ is the number of jumps, $K$ is the number of related variables and $\sum R c^{2}$ is the sum of ranks for each column squared. The dependent variables are scaled at the ordinal level and do not need to fit a specific distribution.

Sample size and corresponding statistical power were also considered during the study design phase. However, in studies where this step has been omitted, it is important to calculate and specify effect size as a post-hoc analysis.

To this end we used the following tests to adjust the error. The Bonferroni test may be too conservative to compare times in such a small sample, and its omission could therefore be justified as it could result in a failure to detect certain differences. The Holm test is based on the Bonferroni inequality and is valid regardless of the joint distribution of the test statistics. The Hold procedure is less conservative and hence more powerful than the Bonferroni correction. It uses a stepwise procedure to examine the ordered set of null hypotheses, starting with the smallest $\mathrm{p}$ value and continuing until it is no longer able to reject a null hypothesis.

\section{RESULTS}

Table 1 shows the results for the dependent variables in the Friedman test. With the exception of SL, the values for all the other variables were the highest, and therefore there is sufficient evidence to reject the null hypothesis and conclude that there are significant differences between run-up strides 1-2-3 (table 1).

Calculation of the effect size in the post-hoc tests showed an absence of statistically significant differences between variables a2-a3, SF2-SF3, h2-h3, $\mathrm{t}_{\mathrm{FL}} 2-\mathrm{t}_{\mathrm{FL}} 3$, $\mathrm{t}_{\mathrm{STR}} 2-\mathrm{t}_{\mathrm{STR}} 3$ and $\mathrm{Vy} 2-\mathrm{Vy} 3$. However, significant differences were observed between a1-a2, a1-a3, SF1-SF2, SF1-SF3, h1-h2, h-h3, Ls1-Ls2, Ls2-Ls3, $\mathrm{t}_{\mathrm{C}} 1-\mathrm{t}_{\mathrm{C}} 2$, $\mathrm{t}_{\mathrm{C}} 1-$ $\mathrm{t}_{\mathrm{C}} 3, \mathrm{t}_{\mathrm{C}} 2-\mathrm{t}_{\mathrm{C}} 3, \mathrm{t}_{\mathrm{FL}} 1-\mathrm{t}_{\mathrm{FL}} 2, \mathrm{t}_{\mathrm{FL}} 1-\mathrm{t}_{\mathrm{FL}} 3, \mathrm{t}_{\mathrm{STR}} 1-\mathrm{t}_{\mathrm{STR}} 2, \mathrm{t}_{\mathrm{STR}} 1-$ tsTR , Vr1-Vr2, Vr1-Vr3, Vr2-Vr3, $\mathrm{V}_{\mathrm{STR}} 1-\mathrm{V}_{\mathrm{STR}} 2, \mathrm{~V}_{\mathrm{STR}} 1-$ $\mathrm{V}_{\mathrm{STR}} 2, \mathrm{~V}_{\mathrm{STR}} 2-\mathrm{V}_{\mathrm{STR}} 3, \mathrm{Vx} 1-\mathrm{Vx} 2, \mathrm{Vx} 1-\mathrm{Vx} 3, \mathrm{Vx} 2-\mathrm{Vx} 3$, $\mathrm{Vy} 1-\mathrm{Vy} 2$ and $\mathrm{Vy} 1-\mathrm{Vy} 3$ (table 2).

\section{DISCUSSION}

The results of this study show us which spatiotemporal variables associated with run-up strides in long jumps by blind athletes have a determining effect on jump results, and also allow us to compare findings with those reported for sighted athletes. Few studies have analysed long jump approaches and take-off actions by blind $^{3132}$ or sighted athletes. ${ }^{33}$

Sighted long jump athletes visually regulate their strides and use visual cues such as the position of the take-off board in their approach to the jump, and this visual regulation of stride pattern has been found to correlate positively with jump distance. ${ }^{34}$ The detection of variable foot placement patterns on take-off boards in skilled long jumpers also suggests the use of visual regulation. ${ }^{35}$ Athletes, however, who cannot see or have only minimal light perception, and who are additionally required to wear opaque glasses or similar in competition situations, ${ }^{36}$ need to use auditory cues such as claps or shouts from their guide to orientate themselves with respect to the runway and take-off board. Runway distance is shorter for blind athletes than for sighted athletes. In London 2012, for example, the distance was 22-32 $\mathrm{m}$ for the Paralympic 
Table 2 Post-hoc tests

\begin{tabular}{|c|c|c|c|c|}
\hline Variable & Post-hoc & Statistics & Bonferroni correction & Holm correction \\
\hline \multirow[t]{3}{*}{ a } & a1-a2 & 10.995 & $6.264 \mathrm{e}-10$ & $6.264 \mathrm{e}-10$ \\
\hline & a1-a3 & 10.401 & $1.760 \mathrm{e}-09$ & $1.173 \mathrm{e}-09$ \\
\hline & a2-a3 & 0.594 & 1 & 0.558 \\
\hline \multirow[t]{3}{*}{ SF } & SF1-SF2 & 7.496 & $5.119 \mathrm{e}-07$ & $3.413 e-07$ \\
\hline & SF1-SF3 & 7.764 & $2.898 \mathrm{e}-07$ & $2.898 \mathrm{e}-07$ \\
\hline & SF2-SF3 & 0.267 & 1 & 0.791 \\
\hline \multirow[t]{3}{*}{ h } & h1-h2 & 10.995 & $6.264 \mathrm{e}-10$ & $6.264 \mathrm{e}-10$ \\
\hline & h1-h3 & 10.401 & $1.760 \mathrm{e}-09$ & $1.173 \mathrm{e}-09$ \\
\hline & h2-h3 & 0.5943 & 1 & 0.558 \\
\hline \multirow[t]{3}{*}{$\mathrm{SL}^{*}$} & SL1-SL2 & 3.785 & 0.001 & 0.003 \\
\hline & SL1-SL3 & 0.000 & 1 & 1 \\
\hline & SL2-SL3 & 3.785 & 0.001 & 0.003 \\
\hline \multirow[t]{3}{*}{$t_{C}$} & $t_{c} 1-t_{c} 2$ & 14.247 & $4.131 \mathrm{e}-12$ & $4.131 \mathrm{e}-12$ \\
\hline & $t_{c} 1-t_{C} 3$ & 8.095 & $1.454 \mathrm{e}-07$ & $9.695 \mathrm{e}-08$ \\
\hline & $t_{c} 2-t_{C} 3$ & 6.152 & $1.026 \mathrm{e}-05$ & $3.420 \mathrm{e}-06$ \\
\hline \multirow[t]{3}{*}{$t_{\mathrm{FL}}$} & $t_{F L} 1-t_{F L} 2$ & 11.076 & $5.458 \mathrm{e}-10$ & $5.458 \mathrm{e}-10$ \\
\hline & $t_{F L} 1-t_{F L} 3$ & 9.910 & $4.260 \mathrm{e}-09$ & $2.840 \mathrm{e}-09$ \\
\hline & $t_{F L} 2-t_{F L} 3$ & 1.165 & 0.768 & 0.256 \\
\hline \multirow[t]{3}{*}{$t_{\text {STR }}$} & $t_{\text {STR }} 1-t_{S T R} 2$ & 9.703 & $6.247 e-09$ & $4.165 \mathrm{e}-09$ \\
\hline & $t_{S T R} 1-t_{S T R} 3$ & 10.309 & $2.073 e-09$ & $2.073 e-09$ \\
\hline & $t_{\mathrm{STR}} 2-\mathrm{t}_{\mathrm{STR}} 3$ & 0.606 & 1 & 0.550 \\
\hline \multirow[t]{3}{*}{$\mathrm{Vr}$} & Vr1-Vr2 & 5.716 & $2.841 \mathrm{e}-05$ & $9.473 e-06$ \\
\hline & Vr1-Vr3 & 12.442 & $5.932 \mathrm{e}-11$ & $5.932 \mathrm{e}-11$ \\
\hline & Vr2-Vr3 & 6.725 & $2.778 \mathrm{e}-06$ & $1.852 \mathrm{e}-06$ \\
\hline \multirow[t]{3}{*}{$V_{\text {STR }}$} & $\mathrm{V}_{\mathrm{STR}} 1-\mathrm{V}_{\mathrm{STR}} 2$ & 5.306 & $7.540 e-05$ & $2.513 e-05$ \\
\hline & $\mathrm{V}_{\mathrm{STR}} 1-\mathrm{V}_{\mathrm{STR}} 3$ & 12.382 & $6.509 e-11$ & $6.509 e-10$ \\
\hline & $\mathrm{V}_{\mathrm{STR}} 2-\mathrm{V}_{\mathrm{STR}} 3$ & 7.075 & $1.275 \mathrm{e}-06$ & $8.505 e-07$ \\
\hline \multirow[t]{3}{*}{$V x$} & $V \times 1-V \times 2$ & 5.114 & $1.197 \mathrm{e}-04$ & $3.990 \mathrm{e}-05$ \\
\hline & $V \times 1-V \times 3$ & 14.065 & $5.333 e-12$ & $5.333 e-12$ \\
\hline & $V \times 2-V \times 3$ & 8.951 & $2.612 \mathrm{e}-08$ & $1.741 \mathrm{e}-08$ \\
\hline \multirow[t]{3}{*}{ Vy } & Vy1-Vy2 & 10.889 & $7.517 e-10$ & $7.517 e-10$ \\
\hline & Vy1-Vy3 & 10.578 & $1.289 \mathrm{e}-09$ & $8.596 e-10$ \\
\hline & Vy2-Vy3 & 0.311 & 1 & 0.758 \\
\hline
\end{tabular}

*Not significant.

SL, stride length.

Games compared with $28-44 \mathrm{~m}$ for the Olympic Games. ${ }^{26}$

Numerous authors have found a correlation between speed in the last stages of the run-up and long jump distance. $^{16-23} 253738$ Very few studies, however, have analysed these aspects in blind athletes. ${ }^{32}{ }^{39}$ We will therefore focus on discussing the results of our series and drawing comparisons with reports for athletes with less visual impairment ${ }^{40}$ and elite athletes without visual impairment.

In our series, we found statistically significant differences for BCM velocity between $\mathrm{Vx} 1-\mathrm{V} \times 2, \mathrm{Vx} 1-\mathrm{V} \times 3$ and 
$\mathrm{Vx} 2-\mathrm{Vx} 3$, and a progressive increase in speed through the antepenultimate, penultimate and last stride (8.18$8.26-8.38 \mathrm{~m} / \mathrm{s})$. Reports for visually impaired athletes competing in the F12 and F13 classes (visual field of $<5^{\circ}$ and $<20^{\circ}$ radius, respectively) show that these either decrease or maintain their speed in the last stride of the approach. ${ }^{24} 253139$ Overall, the run-up speeds and jump distances were lower in our series of F11 athletes, supporting previous reports of a correlation between approach speed and effective jump distance. ${ }^{19} 3841$

Instantaneous horizontal velocity $\left(\mathrm{V}_{\mathrm{BCM}}\right)$ recorded for long jump finalists at the International Blind Sports Federation 2009 European Athletics Championships in the last three strides was $8.45-8.82-8.41 \mathrm{~m} / \mathrm{s}$ for $\mathrm{F} 12$ athletes and $8.15-8.37-8.06 \mathrm{~m} / \mathrm{s}$ for $\mathrm{F} 13$ athletes, showing a reduction in horizontal speed in the last stride in both cases. This finding is in contrast to our observations. Higher instantaneous horizontal velocities have been reported for sighted long jumpers in the last two or three strides, with speeds of 9.82-9.82 $\mathrm{m} / \mathrm{s}$ recorded at the 2007 European Cup Athletics Indoor Championships ${ }^{42}$ and of 10.46-10.52-10.40 m/ $\mathrm{s}$ and $10.37-9.63-10.69 \mathrm{~m} / \mathrm{s}$ at the 2009 and 2011 World Championships in Athletics, respectively. ${ }^{24} 43$

In our series, stride speed $\left(\mathrm{V}_{\mathrm{STR}}\right)$, which corresponds to the time between one contact with the ground and the next, was $8.05-9.00-9.60 \mathrm{~m} / \mathrm{s}$ for the last three strides. We are unable to compare these speeds with those achieved by long jumpers in other categories, as stride speed was not analysed in the studies we identified. We believe, however, that this variable is interesting as it provides information on leg action. The increase in stride speed in the last three strides was higher than that observed for BCM (Vx), although we observed no significant differences between $V_{S T R} 1$ $\mathrm{V}_{\mathrm{STR}} 2, \mathrm{~V}_{\mathrm{STR}} 1-\mathrm{V}_{\mathrm{STR}} 3$ and $\mathrm{V}_{\mathrm{STR}} 2-\mathrm{V}_{\mathrm{STR}} 3$ and $\mathrm{Vr} 1-\mathrm{Vr} 2$, Vr1-Vr3 and Vr2-Vr3.

Vertical speed at take-off (Vy) was $0.60-0.6-0.40 \mathrm{~m} / \mathrm{s}$ for the last three strides in our series, The corresponding BCM heights were 1.95-2.10-0.85 cm, showing a slight variation in BCM during the strides, although the differences between h2-h3 and Vy2-Vy3 were not significant.

SL measured for the last three strides was the only spatial variable that was not significantly associated with jump result, although the trend detected for SL1 and SL3 is similar to that reported for sighted athletes. A short-long-short stride pattern has been reported for sighted athletes in the final jump approach (ie, a short antepenultimate stride followed by a long penultimate stride and a short last stride). ${ }^{22} 23 \quad 26 \quad 44-47$ An identical pattern has been described for F12 athletes (1.95-2.12-1.88 m) and F13 athletes (1.89-2.00-1.82 $\mathrm{m}){ }^{33}{ }^{40}$ In our series, SL was $1.99-2.20-2.15 \mathrm{~m}$, indicating that F11 athletes do not significantly shorten their last step due to a lack of spatial perception.
$\mathrm{SF}$ in our series $(4.05-4.00-4.50 \mathrm{~Hz})$ was inversely related to SL. The pattern for SF in other studies is high-low-high, while the SL pattern is short-longshort. Using the length and speed data provided for sighted long jump finalists at the 2009 World Championships in Athletics, ${ }^{24}$ we calculated a mean SF of 4.54-4.31-4.73 Hz. As in our series, the antepenultimate, penultimate and last step had the lowest and highest frequencies, respectively, although the differences are smaller. We also compared the last three strides to calculate the relative differences in frequency. In our series, SF first decreased by $4.33 \%$ but then increased by $28.57 \%$. The relative changes for the sighted athletes were much slighter (decreased by $5.04 \%$ and increased by $9.88 \%$ ).

With respect to spatiotemporal variables for the actions executed prior to take-off and during flight, we found no statistical associations between $\mathrm{t}_{\mathrm{FL}} 2-\mathrm{t}_{\mathrm{FL}} 3$ and $\mathrm{t}_{\mathrm{STR}} 2-\mathrm{t}_{\mathrm{STR}} 3$ in our series. We did, however, observe significant differences for $\mathrm{T}_{\mathrm{C}}^{1}-\mathrm{tc}^{2}, \mathrm{t}_{\mathrm{C}} 1-\mathrm{t}_{\mathrm{C}} 3, \mathrm{t}_{\mathrm{C}} 2-\mathrm{t}_{\mathrm{C}} 3, \mathrm{t}_{\mathrm{FL}} 1-$ $\mathrm{t}_{\mathrm{FL}} 2, \mathrm{t}_{\mathrm{FL}} 1-\mathrm{t}_{\mathrm{FL}} 3, \mathrm{t}_{\mathrm{STR}} 1-\mathrm{t}_{\mathrm{STR}} 2$ and $\mathrm{t}_{\mathrm{STR}}{ }^{1-\mathrm{t}_{\mathrm{STR}}} 3$.

Very few studies have analysed contact and flight time in the final approach in long jump competitions, probably due to reservations regarding the accuracy of recordings in some cases. Because we used a $300 \mathrm{~Hz}$ camera, we believe that our results for these times are reliable. The contact times were $0.126-0.120-0.139 \mathrm{~s}$ for the last three strides.

An average board contact time of $0.120 \mathrm{~s}$ has been reported for sighted athletes. ${ }^{48}$ In our series, the mean contact with the take-off board was $0.134 \mathrm{~s}$. As the aim of this board is to transfer run-up speed to take-off speed, it would only be logical that these speeds would correlate most closely with effective jump distance.

\section{CONCLUSIONS}

In this study of the actions of blind long jumpers, we found that the athletes, unlike those without disabilities, do not vary their leg actions during the final runway approach for optimal placement on the takeoff board.

The number of strides regulated by sensory orientation in the run-up was positively correlated with jump distance. Accordingly, sensory orientation exercises should be used to develop spatial perception in blind people.

Acknowledgements Thanks to the International Paralympic Committee.

Contributors MAT and JMP: data collection, results analysis and drafting of article. JLLo and JLLó: results analysis and drafting of the article.

Funding UB-INEFC and Spanish Ministry of Economy and Competitiveness: DEP2015-66069-P; MINECO/ERDF, EU and PSI2015-71947-REDT; MINECO/ ERDF, EU.

Competing interests None declared.

Patient consent Obtained.

Ethics approval The Bioethics Committee at the University of Barcelona (IRB00003099). 
Provenance and peer review Not commissioned; externally peer reviewed.

Open Access This is an Open Access article distributed in accordance with the Creative Commons Attribution Non Commercial (CC BY-NC 4.0) license, which permits others to distribute, remix, adapt, build upon this work noncommercially, and license their derivative works on different terms, provided the original work is properly cited and the use is non-commercial. See: http:// creativecommons.org/licenses/by-nc/4.0/

(c) Article author(s) (or their employer(s) unless otherwise stated in the text of the article) 2017. All rights reserved. No commercial use is permitted unless otherwise expressly granted.

\section{REFERENCES}

1. Burkett B. Technology in Paralympic sport: performance enhancement or essential for performance? $\mathrm{Br} J$ Sports Med 2010;44:215-20.

2. Gregory RL. Perceptual illusions and brain models. Society R, ed. Logical analysis of cerebral functions. 171. London: Royal Society, 1968:279-96.

3. Gregory RL. Knowledge in perception and illusion. Philos Trans $R$ Soc Lond B Biol Sci 1997;352:1121-7.

4. Gregory R. Brainy mind. BMJ 1998;317:1693-5.

5. Gregory R. Perception. Percept Ed 2004;33:895-6.

6. G. J, A S. Organizational behaviour: understanding and managing life at work with MyOBLab. 8th ed. Upper Saddle river, NJ: Pearson Education Inc, 2010

7. Palmi J. La percepción: enfoque funcional de la visión. Apunt EF 2007;2:81-5.

8. Codina M. La discapacidad visual. Atletismo adaptado para personas ciegas y deficientes visuales. Barcelona: Paidotribo, 2004:15-29.

9. Rosa A, Ochaíta E. PsicologÚa de la ceguera. Alianza Ps. Madrid, 1993.

10. Dolins F, Mitchell R. Spatial cognition, spatial perception: mapping the self and space. New York: Cambridge Press, 2010.

11. Hatfield G. The natural and the normative: theories of spatial perception from Kant to Helmholtz. Cambridge: MIT Press, 1990.

12. Committee IP. Athletics classification. Rules and regulations 2011 2016 https://www.paralympic.org/athletics/classification/rules-andregulations (accessed $10 \mathrm{Apr} 2016$ ).

13. Tweedy SM, Vanlandewijck YC. International paralympic committee position stand-background and scientific principles of classification in paralympic sport. Br J Sports Med 2011;45:259-69.

14. Webborn AD. Fifty years of competitive sport for athletes with disabilities: 1948-1998. Br J Sports Med 1999;33:138.

15. Ravensbergen H, Mann D, Kamper S, et al. No title. Br J Sport Med 2016 http://bjsm.bmj.com/content/early/2016/02/17/bjsports-2015-0 95434.full.

16. Bridgett LA, Linthorne NP. Changes in long jump take-off technique with increasing run-up speed. J Sports Sci 2006;24:889-97.

17. Bruggemann G, Conrad T. Biomechanical research in athletics-1st world junior championships, athens 1986. In: Susanka P P Bruggemann G-P, Tsarouhas E, eds. Athletics-1st world junior championships. Athens: SEGAS \& EKAE, 1986:89-119. p.

18. Fukashiro $S$. et alEvaluation of the efficient motion in the running long jump. In: Tsarouchas L, Terauds J, Gowitzke BA, Holt LE, . eds. Biomechanics in Sports V. Athens: HSRI, 1989:104-11.

19. Hay JG, Miller JA, Canterna RW. The techniques of elite male long jumpers. J Biomech 1986;19:855-66.

20. Hay JG, Citius HJ. Citius, altius, longius (faster, higher, longer): the biomechanics of jumping for distance. J Biomech 1993;26:7-21.

21. Hay JG, Miller JA. Techniques used in the transition from approach to takeoff in the long jump. Int J Sport Biomech 1985;1:174-84.

22. Hay JG, Nohara H. Techniques used by elite long jumpers in preparation for takeoff. J Biomech 1990;23:229-39.

23. Koyama $\mathrm{H}$, Muraki $\mathrm{Y}, \mathrm{Ma} A \mathrm{AE}$. Target value for the maximum run-up speed of the long jump based on the performance level. Port $J$ Sport Sci 2011;11:299-302.
24. Mendoza L, Nixdorf E. Biomechanical analysis of the horizontal jumping events at the 2009 IAAF world championships in athletics. New Stud Athl 2011;26:25-60.

25. Panoutsakopoulos V, Papaiakovou G, Katsikas FS, et al. 3D Biomechanical analysis of the preparation of the long jump take-off. New Stud Athl 2010;25:55-68.

26. Schiffer J. The horizontal jumps. New Stud Athl 2011;26:139-64.

27. Hay JG. Approach Strategies in the Long Jump. Int J Sport Biomech 1988;4:114-29.

28. Montagne G, Cornus S, Glize D, et al. A perception-action coupling type of control in long jumping. J Mot Behav 2000;32:37-43.

29. Nojima O. Development of high speed digital camera: EXILIM EX-F1. J Soc Photogr Sci Technol Japan 2011;72:195-8.

30. Balsalobre-Fernández C, Tejero-González CM, del Campo-Vecino J, et al. The concurrent validity and reliability of a low-cost, high-speed camera-based method for measuring the flight time of vertical jumps. J Strength Cond Res 2014;28:528-33.

31. Theodorou A, Skordilis E. Evaluating the approach run of class F11 visually impaired athletes in triple and long jumps. Percept Mot Skills 2012;114:595-609.

32. Torralba M, Padullés J, Braz M, et al. Cinemática del salto de longitud de personas ciegas. 19: EFDeportes.com, 2015. http:// www.efdeportes.com/efd201/salto-de-longitud-de-personas-ciegas. htm

33. Theodorou A, Skordilis E, Plainis S, et al. Stride length regulation at the approach phase of long jump in visually impaired (F12 class) athletes. In: Bradshaw E, Burnett A, PA H, Proceedings of the 30th International Congress in Sports Biomechanics. Melbourne, 2012:33-6.

34. Bradshaw EJ, Aisbett B. Visual guidance during competition performance and run-through training in long jumping. Sports Biomech 2006;5:1-14.

35. Scott MA, Li FX, Davids K. Expertise and the regulation of gait in the approach phase of the long jump. J Sports Sci 1997;15:597-605.

36. International Paralympic Committee. Athletics rules and regulations [Internet]. 2016 https://www.paralympic.org/sites/default/files/ document/1604281540295512015 12+IPC+Athletics+Rules+and +Regulations_A4_WEB2.pdf (accessed 20 Apr 2016).

37. Hay JG. The biomechanics of the long jump. Exerc Sport Sci Rev 1986;14:401-46.

38. Nixdorf E, Brüggemann GP. Biomechanical analysis of the long jump scientific research project at the games of the XXIVth Olympiad Seoul 1988. Italy 1990.

39. Theodorou A, Skordilis E, Tasoulas E, et al. Stride regulation at the approach phase of long jump in visually impaired. Port J Sport Sci 2011;11:395-7.

40. Panoutsakopoulos V, TheodorouA, Kotzmanidou M, et al. Biomechanical analysis of the final strides of the approach and the take-off by visually impaired class F12 and F13 long jumpers. J Hum Sport Exerc 2013 http://www.jhse.ua.es/jhse/article/view/599/830

41. Lees A, Fowler N, Derby D. A biomechanical analysis of the last stride, touch-down and take-off characteristics of the women's long jump. J Sports Sci 1993;11:303-14.

42. Panoutsakopoulos V, Papaiakovou GI. 3D Biomechanical analysis of the preparation of the long jump take-off. New Stud Ath 2010;25:55-68.

43. Kim E-H, Bae Y-S, Et All. Biomechanics research project in the IAAF world championships daegu 2011. Korean Soc Sport Biomech 2011;55:46.

44. Kim H-M, Woo S-Y, Kim Y-W, et al. Kinematic Analysis of Women's Long Jump at IAAF World Championships, Daegu 2011. Korean Journal of Sport Biomechanics 2011;21:603-10.

45. Muller H, Brüggemann G. Long Jump. New Stud Athl 1997;13:56-9.

46. Seo J-S, Woo S-Y, Kim Y-W, et al. Kinematic analysis of the men's long jump in the IAAF world championships daegu 2011. Korean J Sport Biomech 2011;21:595-602.

47. Shimizu Y, Ae M, Koyama H. A biomechanical study of the takeoff preparation and the takeoff motions in elite male long jumpers. Port J Sport Sci 2011;11:381-3.

48. Ballreich R, Brüggemann G. Weitsprungs Bdes. Verlag $\mathrm{E}$ Biomechanik der Sportarten. Stuttgart: Band 1: Biomechanik der Leichtathletik, 1986. 